\title{
IMPLEMENTASI PENGELOLAAN PERPUSTAKAAN DI MADRASAH SWASTA
}

\author{
Wawan Hermawan \& Ari Prayoga \\ UIN Sunan Gunung Djati Bandung \\ hajiwawanhermawan@gmail.com , ariprayoga@madrasah.id
}

\begin{abstract}
The book collection has not been properly inventoried, student interest in reading visits is still low, supervision is carried out every $2 / 3$ months, there is a loss of inventory of madrasa library books, the head of the library does not have staff resources. The purpose of this study is to uncover and analyze the management process including; planning, implementing, organizing, monitoring and evaluating libraries in Madrasah Aliyah Darussalam Sumedang, Indonesia. This research method is descriptive with a qualitative approach. Data collection techniques use; study interviews with the head of the library as the key informant and head of the madrasa, study documents include, book archives, library work programs, library visit books; Observation studies record library activity activities, discussion processes, weekly meetings. The results showed that; first, planning is carried out with the madrasa head at the madrasa level meeting by submitting a work program and submitting a draft budget (RAB); second, organizing is regulated based on the statement of the headmaster of madrasa no: $M A . i$ / S / 20 / pp.006 / 001/2019 concerning the additional duties of Elyana Barbera as head of the library and does not yet have accompanying staff; third, the program implementation at the library is carried out by the head of the library, namely borrowing books, daily library services, work program socialization; fourth, supervision is carried out incidentally monthly and weekly, direct and indirect visits through work program reports to the madrasah head; an evaluation is carried out at the end of the school academic period by submitting a report on the overall madrasa library management program.
\end{abstract}

Keywords: Management, Library, Madrasa.

\begin{abstract}
Abstrak : Koleksi buku belum terinventarisir dengan baik, kunjungan minat baca siswa masih rendah, pengawasan dilaksanakan $2 / 3$ bulan sekali, terjadinya kehilangan inventarisasi buku perpustakaan madrasah, kepala perpustakaan tidak memiliki sumber daya staf. Tujuan penelitian ini yaitu untuk mengungkap dan menganalisis proses pengelolaan meliputi; perencanaan, pelaksanaan, pengorganisasian, pengawasan dan evaluasi perpustakaan di Madrasah Aliyah Darussalam Sumedang, Indonesia. Metode penelitian ini deskriptif dengan pendekatan kualitatif. Teknik pengumpulan data menggunakan; studi wawancara bersama kepala perpustakaan sebagai key informan dan kepala madrasah, studi dokumen meliputi, arsip buku, program kerja perpustakaan, buku kunjungan perpustakaan; studi observasi merekam aktivitas kegiatan kunjungan perpustakaan, proses diskusi, rapat mingguan. Hasil penelitian menunjukan bahwa; pertama, perencanaan dilaksananakan bersama kepala madrasah pada rapat tingkat madrasah dengan menyampaikan program kerja dan pengajuan rancangan anggaran belanja (RAB); kedua, pengoorganisasian diatur berdasarkan surat keterangan kepala madrasah no: MA.i/S/20/pp.006/001/2019 tentang tugas tambahan
\end{abstract}

Manazhim : Jurnal Manajemen dan Ilmu Pendidikan

Volume 2, Nomor 1, Februari 2020; 29-44

https://ejournal.stitpn.ac.id/index.php/manazhim 
Elyana Barbera sebagai kepala perpustakaan dan belum memiliki staf pendamping; ketiga, pelaksanaan program pada perpustakaan dilaksanakan oleh kepala perpustakaan yaitu peminjaman buku, pelayanan perpustakaan harian, sosialisasi program kerja; keempat, pengawasan dilaksakan secara insidental bulanan dan mingguan, secara langsung kunjungan dan tidak langsung melalui laporan program kerja pada kepala madrasah; evaluasi dilaksakanan pada akhir periode akademik sekolah dengan menyampaikan laporan secara keseluruhan program pengelolaan perpustakaan madrasah.

Kata Kunci: Pengelolaan, Perpustakaan, Madrasah.

\section{PENDAHULUAN}

Perpustakaan sebagai jantung dari ilmu pengetahuan yaitus sebuah ungkapan sebagai media dalam membangun budaya literasi. Jika pendidikan diibaratkan sebagai badan, maka perpustakaan sebagai jantungnya. Bila perpustakaan memiliki standarisasi yang baik maka akan berjalan pula dengan baik pelayanan pendidikan literasinya. Sangat ironis bila dalam dunia pendidikan sebagai jalan menggapai ilmu pengetahuan ternyata masih kurang atau bahkan kurang memperdulikan dengan keberadaan dan keadaan perpustakaan ${ }^{1}$. Pengelolaan perpustakan memang bukanlah problematika yang baru muncul akan tetapi banyak orang yang salah mengasosiasikan perpustakaan dengan buku-buku. Sehingga setiap tumpukan buku-buku disuatu tempat disebut perpustakaan. Perpustakaan memang memiliki sebuah ciri khas utama yaitu dengan adanya buku akan tetapi bukan berarti setiap ada penumpukan buku lalu dapat dikatakan sebagai perpustakaan. Perpustakaan memiliki arti yang lebih spesifik yakni ruang khusus dengan mekanisme tata kerja yang khusus ${ }^{2}$.

Secara umum banyak permasalahan yang dihadapi petugas perpustakaan dalam pengelolaan perpustakaan. Persoalan yang sering selalu muncul dalam pengelolaan perpustakaan yaitu dari segi dana pengelolaan dan fokus prioriras yang kurang, baik dari pemerintah atau internal lembaga karena arus digitalisasi informasi. Hal inilah yang mengakibatkan beberapa perpustakaan masih kurang diminati oleh anak muda milenial yang lebih suka mengakses bahan bacaan melalui handphone pintar. Hal seperti itu juga dapat dilihat pada fenomena sebagai berikut: 1) rendahnya persentase anggaran yang dialokasikan untuk perpustakaan; 2) rendahnya perencanaan program pengembangan perpustakaan, implementasi dan evaluasi; 3)

${ }^{1}$ Sugeng Agus Priyono, Perpustakaan Atraktif, 1st edn (Jakarta: PT. Gramedia Pustaka Utama, 2006).

2 Ibrahim Bafadal, Pengelolaan Perpustakaan Sekolah, 1st edn (Jakarta: Bumi Aksara, 2009). 
kurangnya upaya pemerintah mencari pendanaan perpustakaan; 4) lemahnya upaya pengintegrasian pelayanan perpustakaan dengan kurikulum sekolah ${ }^{3}$.

Banyak pihak pada dunia pendidikan yang seharusnya ikut terlibat dalam keberlangsungan pengelolaan perpustakaan akan tetapi masih belum memaksimalkan peran dan fungsinya sehingga melupakan tanggung jawab bersama dalam merawat dan menyelenggarakan budaya literasi di perpustakaan. Misalnya, pada penyusunan Rencana Anggaran Pendapatan dan Belanja Sekolah (RAPBS), alokasi pendanaan untuk pengelolaan perpustakaan madrasaah kurang menjadi prioritas. Jikalau pun ada hanya sebatas honor untuk petugas perpustakaan, sedangkan alokasi dana untuk penambahan koleksi buku, pemeliharaan koleksi dan pemeliharaan sarana prasarana perpustakaan lain yang belum mendapatkan perhatian. Pada lembaga madrasah negeri secara umum, tugas pada perpustakaan termasuk sebagai tugas tambahan untuk seorang pendidik yang memiliki kekurangan jam tatap muka mengajar sehingga tidak perlu diberi insentif tambahan atau khusus untuk tugas tambahannya tersebut ${ }^{4}$.

Hal diatas mengakibatkan, pengelolaan pada perpustakaan kurang maksimal dan cenderung masih kurang fokus serta kondusif. Sehingga perpustakaan yang sedang dikelola hanya dijadikan sebagai gudang buku, gedung peralatan dan peralatan lainnya, jarang dibuka apalagi dipergunakan melayani para penggunanya (peserta didik). Padahal jika dikelola dengan baik, perpustakaan di madrasah dapat dimaksimalkan sebagai media edukasi literasi intensif yang sangat membantu dalam proses belajar mengajar dan perpustakaan dapat dijadikan sebagai pusat kegiatan belajar mengajar, pusat penelitian literasi sederhana, pusat membaca, bahkan bisa dijadikan sebagai tempat rekreasi yang nyaman bagi peserta didik. Beberapa penelitian terdahulu telah membuktikan peran penting perpustakaan dalam dunia pendidikan, seperti peran perpustakaan terhadap peningkatan minat baca peserta didik dan peran perpustakaan terhadap prestasi belajar peserta didik ${ }^{5}$.

Fenomena yang terjadi di lokasi penelitian saat ini di Madrasah Aliyah Darussalam Sumedang yaitu minimnya anggaran untuk pengembangan koleksi

\footnotetext{
${ }^{3}$ Ridwan A. Siregar, Perpustakaan: Energi Pembangunan Bangsa, 4th edn (Medan: USU Press, 2004).

${ }^{4}$ Ari Prayoga and Arif Risnandi, 'Manajemen Pembiayaan Pendidikan Di Madrasah Aliyah Darussalam Sumedang', Cakrawala: Jurnal Manajemen Pendidikan Islam Dan Studi Sosial, 03.02 (2019), 117-31 $<$ https://doi.org/10.12345/cakrawala.v3i2.148>.

5 Mohammad Mansyur, 'Manajemen Perpustakaan Sekolah', Pustakaloka, 07.01 (2016), 43-54 <https://doi.org/10.21154/pustakaloka.v7i1.184>.
} 
perpustakaan madrasah. Sumberdaya Pendidik yang diberikan tugas tambahan sebagai pengelola perpustakaan yaitu Elyana Barbera tidak memiliki latar belakang sebagai pustakawan dan tidak memiliki staf dalam mengelola perpustakaan madrasah. Perpustakaan dijadikan sebagai tempat untuk kelas diskusi ketika mata pelajaran berlangsung untuk penggunaan buku, akan tetapi jarang dibuka secara rutin dalam waktu-waktu kegiatan belajar berlangsung. Ketika jam istirahat berlangsung perpustakaan dibuka hanya untuk digunakan sebagai tempat beribadah peserta didik khususnya perempuan. Koleksi buku seringkali hilang karena kurangnya pendataan dan pengawasan dari pengelola perpustakaan. Peminjaman yang kurang administratif dalam catatan peminjaman juga menjadi faktor hilangnya koleksi buku-buku madrasah yang ada di perpustakaan ${ }^{6}$.

Pada Keputusan Menteri Pendayagunaan Aparatur Negara Nomor 18 Tahun 1988, pemerintah telah memberikan perhatiannya khusus terhadap keberadaan perpustakaan di sekolah/madrasah. Khusus untuk sumber daya pengelola perpustakaan berstatus Pegawai Negeri Sipil (PNS) digolongkan kepada tenaga fungsional yang mendapat tunjangan khusus. Pada Undang-undang Nomor 20 disebutkan bahwa Standar Nasional Pendidikan terdiri atas standar isi, proses, kompetensi lulusan, tenaga kependidikan, sarana dan prasarana, pengelolaan, pembiayaan, dan penilaian pendidikan, yang harus ditingkatkan secara berencana dan berkala pada Pasal 35 ayat $1^{7}$. Selanjutnya pasal tersebut diperjelas dengan Pasal 42 ayat 2 yang berbunyi Setiap satuan pendidikan wajib memiliki prasarana yang meliputi ${ }^{8}$; lahan, ruang kelas, ruang pimpinan satuan pendidikan, ruang pendidik, ruang tata usaha, ruang perpustakaan, ruang laboratorium, ruang bengkel kerja, ruang unit produksi, ruang kantin, instalansi daya dan jasa, tempat olah raga, tempat beribadah, tempat bermain, tempat rekreasi, dan ruang tempat-tempat lain yang dibutuhkan sebagai penunjang proses belajar mengajar yang teratur dan berkelanjutan?. Dari pembahasan latar belakang maka perlu adanya kajian lebih

${ }^{6}$ N.Rina Hayati, 'Data Wawancara Kepala Madrasah Aliyah Darussalam Sumedang' (Sumedang: MAS Darussalam, 2019).

7 Kementerian Hukum dan HAM, Undang-Undang Nomor 20 Tabun 2003 Tentang Sistem Pendidikan Nasional (Indonesia, 2003).

${ }^{8}$ Kementerian Hukum dan HAM, Peraturan Pemerintah Nomor 32 Tabun 2013 Tentang Standar Nasional Pendidikan (Indonesia, 2013).

${ }_{9}$ N.S. Sutarno, Perpustakaan Dan Masyarakat (Jakarta: Yayasan Obor, 2003). 
medalam terkait implementasi pengelolaan perpustakaan di Madrasah Aliyah Darussalam Sumedang.

\section{METODE DAN PENDEKATAN PENELITIAN}

Jenis penelitian ini adalah penelitian kualitatif dengan pendekatan deskriptif, artinya penelitian yang ditujukan untuk mendeskripsikan data yang telah dikumpulkan berupa kata-kata dari informan, data tertulis, data gambar dan bukan berupa angka ${ }^{10}$. Lokasi penelitian ini berada di Madrasah Aliyah Darussalam Sumedang Jalan Serma Muchtar Baru Nomor 01, Kelurahan Situ, Kecamatan Sumedang Utara, Kabupaten Sumedang 45323. Adapun alasan peneliti memilih lokasi ini dikarenakan kualitas dan pengelolaan perpustakaan madrasah masih kurang memadai dan kurang dimaksimalkan keberadaannya.

Sumber data primer yaitu data yang diperoleh peneliti secara langsung dari informan kunci yaitu; Kepala Perpustakaan Elyana Barbera, Kepala Madrasah N. Rina Hayati dan peserta didik. Sedangkan sumber data sekunder yaitu data yang diperoleh peneliti dari sumber yang sudah ada seperti; Studi dokumentasi, dengan menyelidiki benda-benda tertulis seperti dokumentasi kunjungan perpustakaan, inventarisasi buku perpustakaan, struktural organigram perpustakaan MAS Darussalam Sumedang, visi dan misi, serta tujuan sekolah. Metode pengumpulan data meliputi ${ }^{11}$; studi observasi, sebagai pengamatan serta pencatatan dengan sistematik fenomena-fenomena yang terjadi dislokasi penelitian; Studi observasi sebagai media untuk mengumpulkan datadata tingkah laku kepala perpustakaan dalam melaksanakan pengelolaan ataupun proses terjadinya kegiatan perencanaan dan evaluasi program layanan perpustakaan; Studi wawancara, pengumpulan data melalui proses tanya jawab secara lisan yang berlangsung antara peneliti bersama kepala perpustakaan, kepala madrasah, dan peserta didik Madrasah Aliyah Darussalam Sumedang ${ }^{12}$.

Dalam pengujian keabsahan data, penelitian ini menggunakan teknik triangulasi, dengan meninjau kebenaran data dokumen yang didapat dengan data yang diperoleh; kecukupan referensial, teknik pengujian keabsahan data dengan cara

\footnotetext{
${ }^{10}$ Lexy J. Moleong, Metode Penelitian Kualitatif (Bandung: Remaja Rosdakarya, 2004).

11 Sugiyono, Metode Penelitian Kuantitatif, Kualitatif Dan R\&D, 24th edn (Bandung: Alfabeta, 2016).

12 Suharsimi Arikunto, Prosedur Penelitian Suatu Pendekatan Praktek (Jakarta: PT. Rineka Cipta, 2002).
} 
melengkapi pengumpulan data dengan perekam suara, kamera foto, dan kamera video $^{13}$. Teknik analisis data sebagai cara mencari serta menyusun secara sistematis catatan hasil dokumentasi, observasi, wawancara, untuk meningkatkan serta memahamkan peneliti tentang Pengelolaan Perpustakaan di Madrasah Aliyah Darussalam Sumedang.

\section{HASIL DAN PEMBAHASAN}

\section{Perencanaan pada Perpustakaan Madrasah}

Perencanaan pada perpustakaan disini mencakup, tujuan, aksi, sumber daya, dan standar ${ }^{14}$. Tujuan organisasi perpustakaan sebagai suatu pernyataan tentang keadaan yang organisasi maksud untuk merealisasikan program pelayanan aliterasi dan sebagai pernyataan tentang keadaan di waktu yang akan datang dimana organisasi sebagai kolektifitas mencoba untuk mengimplementasikannya. Salah satu tujuan perpustakaan yaitu mencari cara membuat peserta didik senang membaca buku, menjadikan membaca sebagai sebuah kebutuhan serta mempunyai rasa ingin tahu untuk mencari informasi di perpustakan, juga sebagai penunjang dalam proses pembelajaran peserta didik dan tenaga pendidik, agar peserta didik memiliki pengetahuan dan wawasan yang luas. Seharusnya perpustakaan madrasah terbaik dapat menyegarkan, mencerdaskan, mencerahkan dan melejitkan prestasi peserta didik dalam membaca dan menggali sumber informasi ${ }^{15}$.

Fungsi dari perencanaan meliputi lima elemen dasar yaitu; tujuan, aksi, sumber daya, standar dan target ${ }^{16}$. Tujuan/Visi misi perpustakaan Madrasah Aliyah Darussalam Sumedang adalah "Ulil Albab" (Unggul, Ilmiah, Amaliah, Ibadah dan Bertanggung jawab), membuat peserta didik senang membaca menggali informasi, menjadikan membaca sebagai kebutuhan peserta didik dan mempunyai ghirah dan gairah untuk mencari informasi cetak di perpustakaan. Selain hal diatas juga bertujuan

13 Philip Buckley and Irawan Irawan, 'The Scientific Paradigm of Islamic Education Management: Phenomenology Perspective', Jurnal Pendidikan Islam, $02.01 \quad$ (2015), 1-29 $<$ https://doi.org/10.15575/jpi.v2i1.701>.

14 Mia Nurdiana and Ari Prayoga, 'Fungsi-Fungsi Manajemen Dalam Kegiatan Ekstrakurikuler Pramuka Di Madrasah', Madrasa: Journal of Islamic Educational Management, 1.0 (2018), 9-15 $<$ https://doi.org/10.32940/mjiem.v1i0.2>.

15 T. Hani Handoko, Manajemen Personalia Dan SDM, 2nd edn (Jakarta: BPFE, 1992).

${ }^{16}$ Ari Prayoga and others, 'Implementasi Penjaminan Mutu Madrasah', Muróbbî: Jurnal Ilmu Pendidikan, 03.01 (2019), 70-84. 
untuk mengembangkan minat baca peserta didik. Pada dasarnya perpustakaan di Madrasah Aliyah Darussalam Sumedang memiliki tujuan yang sama, yakni menjadikan perpustakaan sebagai perpustakaan yang terbaik serta sebagai wahana inspiratif yang mampu mengembangkan minat baca peserta didik agar senang membaca sehingga pengetahuan serta wawasan bertambah secara global.

Aksi dari kegiatan lebih spesifik direncanakan untuk mencapai tujuan lembaga. Kegiatan ini mencakup pengadaan, pengolahan, pelayanan koleksi, dan sosialisasi serta pembinaan sumberdaya manusia. Pengadaan koleksi bahan pustaka perpustakaan Madrasah Aliyah Darussalam Sumedang setiap tahunnya dari DIPA, Komite madrasah dan sumbangan wajib bagi siswa kelas dua belas (XII) ketika akan lulus. Rencana pembelian bahan-bahan koleksi terutama buku berdasarkan penyebaran kertas usulan para pendidik maupun peserta didik yang diberikan pada awal tahun akademik sebelum pembelian buku-buku bacaan. Kegiatan yang sering dilaksanakan oleh pengurus perpustakaan masih sangat minim. Kegiatan yang dilaksanakan tersebut bergantung kepada jenis kegiatan insidental hanya pada saat kegiatan bersih-bersih madrasah baru pengelola dan peserta didik membantu membereskan perpustakaan madrasah. Namun pada dasarnya kegiatan inti di perpustakaan adalah pengadaan, pengolahan, pelayanan koleksi, sosialisasi dan pembinaan. Sebuah rencana harus menspesifikasi jenis dan jumlah sumber daya yang diperlukan.

Pada dasarnya agenda pada perpustakaan apapun bentuknya agar dapat berjalan dalam melaksanakan tugas dan fungsinya ketika mengelola perpustakaan harus ditopang dengan ketersediaan pendanaan yang memadai secara operasional. Setelah anggaran tersedia, madrasah memperhatikan bagaimana mendayagunaannya dengan seefektif dan efisien mungkin, sesuai dengan prosedur administrasi pembiayaan di internal madrasah, tidak terjadi pemborosan ketika pengadaan buku, penyalahgunaan atau bahkan penyimpangan pembelian perpustakaan agar dapat memberikan kontribusi untuk kemajuan sebagaimana diharapkan oleh kepala madrasah dan seluruh stake holder madrasah ${ }^{17}$.

${ }^{17}$ Iwan Sopwandin, Nina Nurmila, and Wahyu Hidayat, 'Fungsi-Fungsi Manajemen Di Perpustakaan Madrasah', Madrasa: Journal of Islamic Educational Management, 02.01 (2019), 23-32 $<$ https://doi.org/10.32940/mjiem.v2i1.117>. 
Hasil data usulan yang memiliki skor tinggi dijadikan sebagai prioritas pembelian koleksi pustaka. Pengolahan labeling buku di perpustakaan Madrasah Aliyah Darussalam Sumedang langsung dikerjakan ketika buku baru tersebut datang. Penyelesaian pengolahan agak terhambat karena perpustakaan memang mengalami kekurangan sumber daya manusia. Buku yang sudah diulas ataupun buku baru tetap diperhatikan pengelolaannya. Pelayanan perpustakaan Madrasah Aliyah Darussalam Sumedang pada jam istirahat masih kurang maksimal karena keterbatasan sumberdaya manusia, pelayanan dilaksanakan dengan cara memberdayakan piket harian peserta didik. Prosedur kunjungan masuk yaitu para peserta didik mengisi buku kunjungan, lalu mencari dan memilih langsung buku di rak. Pada ruangan perpustakaan belum memiliki komputer khusus untuk mendata buku-buku secara digital sebagai basis data pencarian pada rak buku. Buku yang diminati bisa langsung dibaca dalam ruangan, perpustakaan masih belum bisa meminjamkan buku kepada peserta didik karena masih belum adanya sirkulasi buku yang berjalan. Bila hendak dipinjam atau dibawa pulang, dicatatkan langsung oleh petugas dengan menyerahkan kartu pelajar sebagai media penjaminan buku dikembalikan. Bila pendidik yang meminjam untuk dibawa pulang, buku cukup dicatatkan kepada petugas perpustakaan, lalu langsung boleh dibawa.

Sosialisasi sebagai media promosi untuk meningkatkan jumlah pengunjung perpustakaan Madrasah Aliyah Darussalam Sumedang membuat rencana kegiatan berupa penugasan pekerjaan rumah atau diskusi dari bahan bacaan buku kepada peserta didik dan menyuruh peserta didik untuk mencari informasi tersebut di perpustakaan. Kemudian memberikan reward atau hadiah kepada peserta didik yang aktif dan sering berkunjung ke perpustakaan. Aktif di sini dalam artian meminjam, membaca dan menyimpulkan bacaannya, bukan hanya sekedar hadir ke perpustakaan. Pembinaan sumberdaya perpustakaan Madrasah Aliyah Darussalam Sumedang dilakukan khususnya untuk pengunjung (peserta didik) dengan cara pembuatan sekaligus pemberitahuan dan pemberlakuan peraturan-peraturan di perpustakaan. Cara selanjutnya yaitu dengan pengarahan langsung secara lisan baik berupa teguran ataupun berupa anjuran kepada peserta didik yang datang ke perpustakaan. Pembinaan kepada pengguna lain seperti para tenaga pendidik yaitu berupa anjuran terhadap kesadaran para pendidik tentang arti pentingnya perpustakaan madrasah. 
Pembinaan terhadap petugas perpustakaan dilakukan oleh kepala madrasah secara langsung berupa arahan atau teguran kepada petugas perpustakaan dalam menjalankan tugasnya.

\section{Pengorganisasian pada Perpustakaan di Madrasah}

Berdasarkan surat keputusan Kepala MAS Darussalam Sumedang nomor: MA.i/S/20/pp.006/001/2019 tentang pembagian tugas mengajar dan pembantu kepala MAS Darussalam Sumedang tahun pelajaran 2019/2020 menetapkan bahwa Elyana Barbera sebagai kepala perpustakaan Madrasah Aliyah Darussalam Sumedang. Kepala perpustakaan berada dibawah wakil kepala madrasah bidang kurikulum. Secara struktural kepala perpustakaan di MAS Darussalam Sumedang tidak memiliki staf khusus, sehingga hal tersebut berdampak pada pelayaan yang kurang maksimal kepada para peserta didik. Idealnya setidaknya kepala perpustakaan memiliki staf teknis staf penyusunan, staf sirkulasi buku, staf referensi dan staf membaca ${ }^{18}$. Pengorganisasian perpustakaan Madrasah Aliyah Darussalam Sumedang berada langsung dibawah kepala madrasah khususnya wakil kepala madrasah bidang kurikulum.

Gambar 1. Struktur Organisasi MAS Darussalam Sumedang

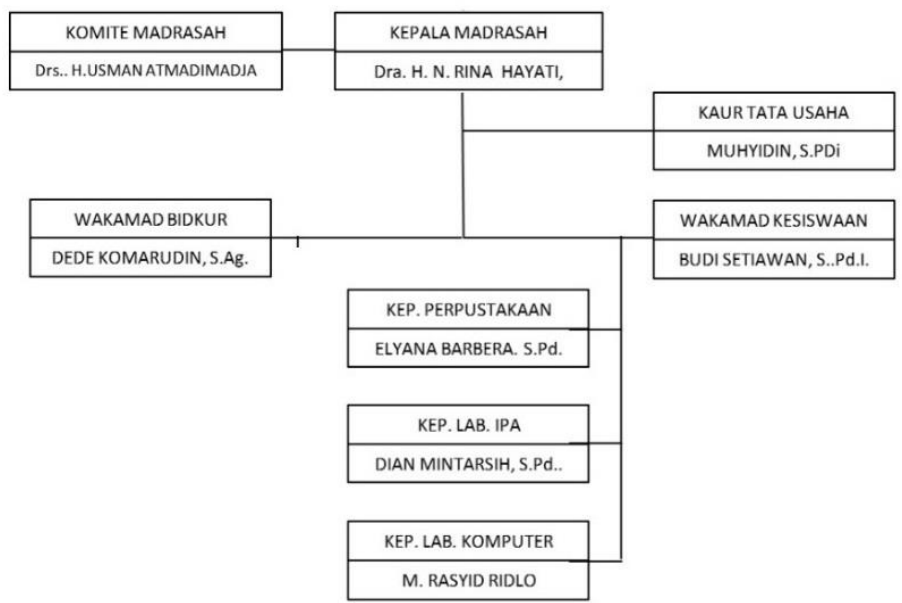

Pengorganisasian meliputi penetapan tugas yang harus dilaksanakan, siapa yang melaksanakan, bagaimana tugas-tugas yang harus dikelompokkan, dan

18 Elyana Barbera, 'Data Wawancara Bersama Kepala Perpustakaan MAS Darussalam Sumedang' (Sumedang: MAS Darussalam, 2019). 
bagaimana semua tugas-tugas tersebut dikoordinasikan ${ }^{19}$. Sebagai hasil dari pengorganisasian adalah pembentukan struktur organisasi. Pengorganisasian perpustakaan tersebut terdiri dari kepala perpustakaan sebagai penanggung jawab dan dibantu para anggotanya yaitu peserta didik yang sukarela meluangkan waktu istirahatnya dibawah bimbingan wakil kepala madrasah bidang kurikulum dan kepala madrasah MAS Darussalam Sumedang. Seharusnya pengorganisasian perpustakaan berada dibawah Wakil Kepala Madrasah Bidang Sarana Prasarana. Sumber daya manusia di perpustakaan merupakan salah satu faktor atau pilar yang sangat penting. Oleh sebab itu harus selalu dikembangkan sesuai dengan kebutuan yang perlu dipenuhi.

Sumber Daya Manusia (SDM), di perpustakaan akan menambah tenaga perpustakaan yang sesuai dengan jurusannya yaitu ilmu perpustakaan. Pengembangan sumber daya manusia di perpustakaan dapat dilakukan dengan mengikutsertakan pada pelatihan yang berkaitan dengan kepustakaan ${ }^{20}$. Pelatihan sebagai sebuah usaha lembaga untuk merencanakan kegiatan dalam membantu sumber daya yang terdapat di perpustakaan madrasah agar memperoleh efektifitas dalam pekerjaannya yang sekarang ataupun yang akan datang melalui pengembangan skill, knowlegde, dan behaviour ${ }^{21}$.

\section{Pelaksanaan Program pada Perpustakaan di Madrasah}

Pelaksanaan dalam perpustakaan yang dimaksud di sini adalah pelaksanaan kerja (actuating) perpustakaan. Pelaksanaan kerja dari setiap unit organisasi mulai dari pimpinan hingga staf-stafnya. Inti manajemen memang kepemimpinan, tetapi manajemen juga harus bertanggung jawab terhadap pelaksanaan pekerjaan. Ini berarti manajemen tidak hanya memerintah tetapi juga melaksanakannya. Pelaksanaan tugas tersebut dimulai dari perencanaan, pengadaan, inventarisasi, klasifikasi (katalogisasi, label buku, kartu buku, slip tanggal dan kantong buku), penyusunan, pelayanan,

19 Ari Prayoga and Arif Risnandi, 'Implementasi Rekrutmen Sumber Daya Manusia Di Madrasah Aliyah Negeri 2 Sumedang', MANAZHIM: Jurnal Manajemen Dan Ilmu Pendidikan, 01.02 (2019), 61-71 $<$ https://doi.org/10.36088/manazhim.v1i2.212>.

${ }^{20}$ R.D. Stueart and B. Moran, Library and Information Center Management, 8th edn (Colorado: Libraries Unlimited, 2002).

${ }^{21}$ Raymond A Noe, Employees Training and Development, ed. by Jane Beck, 5th edn (New York: Mcgraw Hill, 2010). 
pembinaan, sampai kepada evaluasi. Pelaksanaan tugas-tugas dalam perpustakaan tersebut tentu sesuai dengan pembagian tugas kepada unit-unit organisasinya seperti telah dijelaskan pada bagian sebelumnya ${ }^{22}$.

Pembinaan/sosialisasi ketiga perpustakaan yaitu untuk siswa dilakukan diawal masuk ketika MOS diperkenalkan tata cara menggunakan perpustakaan serta pembuatan sekaligus pemberitahuan dan pemberlakuan peraturan-peraturan di perpustakaan, atau dengan cara pengarahan langsung secara lisan baik berupa teguran ataupun berupa anjuran kepada siswa yang datang ke perpustakaan. Pembinaan kepada pengguna lain seperti para guru hanya dalam berupa meminta kesadaran para guru atas arti pentingnya perpustakaan sekolah. Pembinaan terhadap petugas perpustakaan dilakukan oleh kepala sekolah langsung berupa arahan atau teguranteguran kepada petugas perpustakaan dalam menjalankan tugasnya.

Perpustakaan Madrasah Aliyah Darussalam Sumedang tersebut sudah memiliki standar atau pedoman sebagai acuan untuk langkah strategis dan tujuan perpustakaan kedepannya. Pedoman tersebut mengacu pada undang-undang nomor 43 tahun 2007 tentang perpustakaan. Pada Peraturan Menteri Pendidikan Nasional nomor 24 tahun 2007 yaitu tentang Standar Sarana dan Prasarana bagian D. Ketentuan Sarana dan Prasarana nomor 2 Ruang Perpustakaan dapat dijadikan standar fisik yang ingin dicapai oleh sekolah/madrasah, misal perpustakaan SMA/MA sekurang-kurangnya memiliki buku 1 siswa perbandingannya 15 buku, kalau jumlah siswa 800 maka koleksi yang harus setidaknya dimiliki yaitu sebanyak 12.000 buku. Dapat menggunakan pedoman penyelenggaraan perpustakaan sekolah/madrasah yang dikeluarkan oleh Perpustakaan Nasional Republik Indonesia pada tahun 1994 yaitu, dengan berbunyi Perpustakaan Sekolah; petunjuk untuk membina serta memelihara perpustakaan di sekolah/madrasah. Kepala madrasah atau petugas perpustakaan pun ikut serta dalam proses pengelolaannya. Tetapi pada implementasi dilapangan memang yang menjadi kelemahanya yaitu masih belum tercapai secara standar pelayanan minimal di madrasah karena masih terkedala

22 H.A.S. Moenir, Manajemen Pelayanan Umum Di Indonesia, 1st edn (Jakarta: Bumi Aksara, 2003). 
dengan dana yang tersedia. MAS Darussalam baru memiliki koleksi buku dengan jumlah kurang lebih 1344 buku $^{23}$.

Tabel 1. Koleksi Buku MAS Darussalam Sumedang

\begin{tabular}{clcc}
\hline No & \multicolumn{1}{c}{ Jenis Buku } & Jumlah & Ket. \\
\hline 1 & Keagamaan & 654 & IK \\
\hline 2 & Bahasa & 185 & IBB \\
\hline 3 & Ilmu Alam & 177 & IA \\
\hline 4 & Ilmu Sosial & 165 & IS \\
\hline 5 & Lain-lain & 163 & Other \\
\hline
\end{tabular}

\section{Pengawasan dan Evaluasi Program pada Perpustakaan di Madrasah}

Pengawasan terhadap perpustaaan di Madrasah Aliyah Darussalam Sumedang dilaksanakan oleh kepala madrasah yaitu N.Rina Hayati dengan cara datang ke perpustakaan secara langsung dua atau tiga bulan sekali untuk melihat-lihat pengaturan letak buku apakah rapi atau tidak. Secara administratif dipantau dari segi kunjungan setiap 2 minggu sekali. Berdasarkan kepala perpustakaan, pengawasan Kepala madrasah yaitu dengan menanyakan bagaimana kondisi perpustakaan madrasah. Pengawasan juga dilakukan dengan cara meminta laporan atas hasil pelaksanaan kegiatan atau laporan pemanfaatan perpustakaan sekolah dan mencocokkan dengan standar atau ukuran yang telah ditetapkan.

Pengawasan sebagai sebuah proses untuk menjamin bahwa tujuan-tujuan lembaga dan pengelolaan tidak keluar dari tujuan yang telah ditetapkan sehingga tetap pada jalurnya ${ }^{24}$. Ini berkenaan dengan cara-cara dan mekanisme membuat kegiatankegiatan sesuai dengan yang telah direncanakan. Pada pokoknya pengawasan kegiatan yang membandingkan atau mengukur apa yang sedang atau sudah dilaksanakan dengan kriteria, norma-norma, standar atau rencana-rencana yang sudah ditetapkan sebelumnya. Pengawasan perpustakaan di Madrasah Aliyah Darussalam Sumedang perlu dilaksanakan secara intensif mengingat kurangnya sumber daya manusia di

23 Elyana Barbera, 'Data Koleksi Buku Madrasah Aliyah Darussalam Sumedang' (Sumedang: MAS Darussalam, 2019).

${ }^{24}$ Dian Dian and Ari Prayoga, 'Supervisi Akademik Kepala Madrasah Di Madrasah Aliyah Darussalam Sumedang', Briliant: Jurnal Riset Dan Konseptual, $04.04 \quad$ (2019), 548-58 <https://doi.org/10.28926/briliant.v4i4.413>. 
perpustakaan yang mengakibatkan kurang maksimalnya pelayanan pada peserta didik sebagai user.

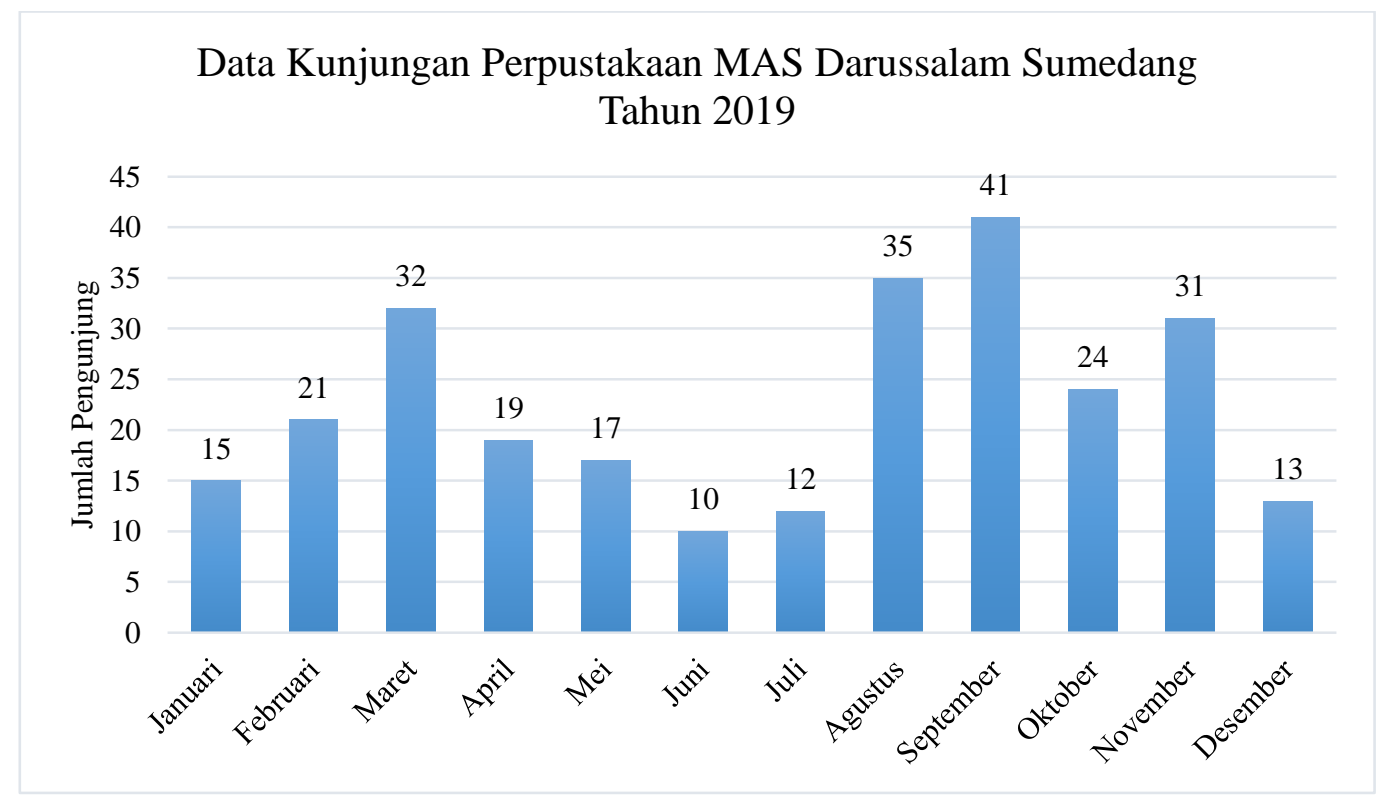

Daftar data diatas menunjukan kunjungan setiap bulannya peserta didik di madrasah. Jika dilihat secara kuantitas masih sedikit peserta didik yang berkunjung untuk membaca atau mencari referensi untuk tugas pembelajaran. Bulan terendah yaitu pada Juni karena pada bulan tersebut memang sedang memasuki libur semester. sedangkan kunjungan terbanyak pada bulan September dengan jumlah 41 orang. Kunjungan masih terhitung naik turun dan tidak stabil. Hal tersebut perlu menjadi perhatian dari petugas perpustakaan dan dapat dijadikan sebagai bahan evaluasi untuk penyusunan program kerja perpustakaan kedepannya, sehingga pada tahun 2020 target minat berkunjung dan membaca peserta didik dapat naik dan memaksimalkan buku-buku madrasah yang sudah ada ${ }^{25}$.

Adapun kepala madrasah menyampaikan bahwa pengawasan mingguan dan bulanan dilaksanakan setiap ada waktu luang, dengan cara menyaksikan secara langsung dan melihat laporan buku daftar pengunjung. Sedang berdasarkan petugas perpustakaan, pengawasan yang dilaksanakan kepala madrasah mengecek secara langsung buku-buku yang sudah diberi kodifikasi atau belum. Pengawasan dapat juga dilaksanakan melalui cara meminta secara langsung laporan hasil pelaksanaan

25 Elyana Barbera, 'Data Dokumen Kunjungan Perpustakaan MAS Darussalam Sumedang' (Sumedang: MAS Darussalam, 2019). 
kegiatan dan laporan pemanfaatan sumberdaya perpustakaan madrasah dan mencocokkannya dengan standarisasi ataupun ukuran yang telah ditetapkan pemerintah $^{26}$.

\section{KESIMPULAN}

Hasil penelitian menunjukan bahwa; pertama, perencanaan dilaksananakan bersama kepala madrasah pada rapat tingkat madrasah dengan menyampaikan program kerja dan pengajuan rancangan anggaran belanja (RAB); kedua, pelaksanaan program pada perpustakaan dilaksanakan oleh kepala perpustakaan yaitu peminjaman buku, pelayanan perpustakaan harian, sosialisasi program kerja; ketiga, pengoorganisasian diatur berdasarkan surat keterangan kepala madrasah no: MA.i/S/20/pp.006/001/2019 tentang tugas tambahan Elyana Barbera sebagai kepala perpustakaan dan belum memiliki staf pendamping; keempat, pengawasan dilaksakan secara insidental bulanan dan mingguan, secara langsung kunjungan dan tidak langsung melalui laporan program kerja pada kepala madrasah; evaluasi dilaksakanan pada akhir periode akademik sekolah dengan menyampaikan laporan secara keseluruhan program pengelolaan perpustakaan madrasah.

Berdasarkan hasil simpulan diatas terdapat beberapa hal yang direkomendasikan untuk kemajuan perpustakaan Madrasah Aliyah Darussalam Sumedang terkait dengan manajemen perpustakaan meliputi; pertama, menambah sarana prasarana perpustakaan yang memadai; kedua, menambah petugas perpustakaan yang profesional sesuai dengan jurusan perpustakaan. Selain itu ada upaya untuk meningkatkan pegawai perpustakaan dengan cara mengikuti diklat atau seminar tentang perpustakaan yang diadakan di luar madrasah; ketiga, menambah koleksi buku baru dan jam berkunjung. Karena rata-rata kebanyakan bukunya berkaitan dengan pelajaran. Maka perlu ada tambahan koleksi baru sebagai buku penunjang. Selain itu jam istirahat perlu ditambah khusus jam berkunjung ke perpustakaan.

26 Suharsimi Arikunto, Dasar-Dasar Evaluasi Pendidikan (Edisi Revisi) (Jakarta: Bumi Aksara, 2019) <http://r2kn.litbang.kemkes.go.id:8080/handle/123456789/61815>. 


\section{DAFTAR PUSTAKA}

Arikunto, Suharsimi, Dasar-Dasar Evaluasi Pendidikan (Edisi Revisi) (Jakarta: Bumi Aksara, 2019) <http://r2kn.litbang.kemkes.go.id:8080/handle/123456789/618 15>

Bafadal, Ibrahim, Pengelolaan Perpustakaan Sekolah, 1st edn (Jakarta: Bumi Aksara, 2009)

Barbera, Elyana, 'Data Dokumen Kunjungan Perpustakaan MAS Darussalam Sumedang' (Sumedang: MAS Darussalam, 2019)

_- 'Data Koleksi Buku Madrasah Aliyah Darussalam Sumedang' (Sumedang: MAS Darussalam, 2019)

- 'Data Wawancara Bersama Kepala Perpustakaan MAS Darussalam Sumedang' (Sumedang: MAS Darussalam, 2019)

Buckley, Philip, and Irawan Irawan, 'The Scientific Paradigm of Islamic Education Management: Phenomenology Perspective', Jurnal Pendidikan Islam, 02 (2015), 129 <https://doi.org/10.15575/jpi.v2i1.701>

Dian, Dian, and Ari Prayoga, 'Supervisi Akademik Kepala Madrasah Di Madrasah Aliyah Darussalam Sumedang', Briliant: Jurnal Riset Dan Konseptual, 04 (2019), 548-58 < https://doi.org/10.28926/briliant.v4i4.413>

Handoko, T. Hani, Manajemen Personalia Dan SDM, 2nd edn (Jakarta: BPFE, 1992)

Hayati, N.Rina, 'Data Wawancara Kepala Madrasah Aliyah Darussalam Sumedang' (Sumedang: MAS Darussalam, 2019)

Kementerian Hukum dan HAM, Peraturan Pemerintab Nomor 32 Tabun 2013 Tentang Standar Nasional Pendidikan (Indonesia, 2013)

_- Undang-Undang Nomor 20 Tabun 2003 Tentang Sistem Pendidikan Nasional (Indonesia, 2003)

Lexy J. Moleong, Metode Penelitian Kualitatif (Bandung: Remaja Rosdakarya, 2004)

Mansyur, Mohammad, 'Manajemen Perpustakaan Sekolah', Pustakaloka, 07 (2016), 43-54 < https://doi.org/10.21154/pustakaloka.v7i1.184>

Moenir, H.A.S., Manajemen Pelayanan Umum Di Indonesia, 1st edn (Jakarta: Bumi Aksara, 2003)

Noe, Raymond A, Employees Training and Development, ed. by Jane Beck, 5th edn (New York: Mcgraw Hill, 2010)

Nurdiana, Mia, and Ari Prayoga, 'Fungsi-Fungsi Manajemen Dalam Kegiatan Ekstrakurikuler Pramuka Di Madrasah', Madrasa: Journal of Islamic Educational Management, 1 (2018), 9-15 <https://doi.org/10.32940/mjiem.v1i0.2>

Prayoga, Ari, and Arif Risnandi, 'Implementasi Rekrutmen Sumber Daya Manusia Di Madrasah Aliyah Negeri 2 Sumedang', MANAZHIM: Jurnal Manajemen Dan Ilmu Pendidikan, 01 (2019), 61-71 <https://doi.org/10.36088/manazhim.v1i2.212> 
_- 'Manajemen Pembiayaan Pendidikan Di Madrasah Aliyah Darussalam Sumedang', Cakrawala: Jurnal Manajemen Pendidikan Islam Dan Studi Sosial, 03 (2019), 117-31 <https://doi.org/10.12345/cakrawala.v3i2.148>

Prayoga, Ari, Azhar Lujjatul Widad, Elin Marliana, Ima Siti Mukarromah, and Uus Ruswandi, 'Implementasi Penjaminan Mutu Madrasah', Muróbbî: Jurnal Ilmu Pendidikan, 03 (2019), 70-84

Priyono, Sugeng Agus, Perpustakaan Atraktif, 1st edn (Jakarta: PT. Gramedia Pustaka Utama, 2006)

Siregar, Ridwan A., Perpustakaan: Energi Pembangunan Bangsa, 4th edn (Medan: USU Press, 2004)

Sopwandin, Iwan, Nina Nurmila, and Wahyu Hidayat, 'Fungsi-Fungsi Manajemen Di Perpustakaan Madrasah', Madrasa: Journal of Islamic Educational Management, 02 (2019), 23-32 <https://doi.org/10.32940/mjiem.v2i1.117>

Stueart, R.D., and B. Moran, Library and Information Center Management, 8th edn (Colorado: Libraries Unlimited, 2002)

Sugiyono, Metode Penelitian Kuantitatif, Kualitatif Dan R\&D, 24th edn (Bandung: Alfabeta, 2016)

Suharsimi Arikunto, Prosedur Penelitian Suatu Pendekatan Praktek (Jakarta: PT. Rineka Cipta, 2002)

Sutarno, N.S., Perpustakaan Dan Masyarakat (Jakarta: Yayasan Obor, 2003) 